Portland State University

PDXScholar

$1-1-2008$

\title{
Correction to "Stochastic comparisons of parallel systems when components have proportional hazard rates"
}

Subhash C. Kochar

Portland State University, kochar@pdx.edu

Maochao Xu

Follow this and additional works at: https://pdxscholar.library.pdx.edu/mth_fac

Part of the Mathematics Commons

Let us know how access to this document benefits you.

Citation Details

Kochar, S., \& Xu, M. (2008). Correction to "Stochastic comparisons of parallel systems when components have proportional hazard rates". Probability in the Engineering \& Informational Sciences, 22(3), 473-474.

This Article is brought to you for free and open access. It has been accepted for inclusion in Mathematics and Statistics Faculty Publications and Presentations by an authorized administrator of PDXScholar. Please contact us if we can make this document more accessible: pdxscholar@pdx.edu. 


\title{
CORRECTION TO "STOCHASTIC COMPARISONS OF PARALLEL SYSTEMS WHEN COMPONENTS HAVE PROPORTIONAL HAZARD RATES"
}

\author{
Subhash Kochar and Maochao Xu \\ Department of Mathematics and Statistics \\ Portland State University, \\ Portland, OR 97201 \\ E-mail:kochar@pdx.edu
}

In our article [3] we have found a gap in the middle of the proof of Theorem 3.2. Therefore, we do not know whether Theorem 3.2 is true for the reverse hazard rate order. However, we could prove the following weaker result for the stochastic order.

THEOREM: Let $X_{1}, \ldots, X_{n}$ be independent random variables with $X_{i}$ having survival function $\bar{F}^{\lambda_{i}}, i=1, \ldots$, n. Let $Y_{1}, \ldots, Y_{n}$ be a random sample with common population survival distribution $\bar{F}^{\bar{\lambda}}$, where $\bar{\lambda}=\sum_{i=1}^{n} \lambda_{i} / n$, then

$$
Y_{n: n}-Y_{1: n} \leq_{\mathrm{st}} X_{n: n}-X_{1: n} .
$$

Proof: From David and Nagaraja [1, p. 26], the distribution function of $R_{X}=X_{n: n}-$ $X_{1: n}$ is, for $x \geq 0$,

$$
F_{R_{X}}(x)=\sum_{i=1}^{n} \int_{0}^{\infty} \lambda_{i} \bar{F}^{\lambda_{i}-1}(u) f(u) \prod_{j=1, j \neq i}^{n}\left[\bar{F}^{\lambda_{j}}(u)-\bar{F}^{\lambda_{j}}(u+x)\right] d u .
$$

Similarly, the distribution function of $R_{Y}=Y_{n: n}-Y_{1: n}$ is, for $x \geq 0$,

$$
F_{R_{Y}}(x)=n \int_{0}^{\infty} \bar{\lambda} \bar{F}^{\bar{\lambda}-1}(u) f(u)\left[\bar{F}^{\bar{\lambda}}(u)-\bar{F}^{\bar{\lambda}}(u+x)\right]^{n-1} d u .
$$


Hence, it is enough to prove, for $u \geq 0, x \geq 0$,

$$
\begin{aligned}
& \sum_{i=1}^{n} \lambda_{i} \bar{F}^{\lambda_{i}-1}(u) f(u) \prod_{j=1, j \neq i}^{n}\left[\bar{F}^{\lambda_{j}}(u)-\bar{F}^{\lambda_{j}}(u+x)\right] \\
& \leq n \bar{\lambda} \bar{F}^{\bar{\lambda}-1}(u) f(u)\left[\bar{F}^{\bar{\lambda}}(u)-\bar{F}^{\bar{\lambda}}(u+x)\right]^{n-1} ;
\end{aligned}
$$

that is,

$$
\sum_{i=1}^{n} \frac{\lambda_{i}}{1-\bar{F}_{u}^{\lambda_{i}}(x)} \prod_{j=1}^{n}\left[1-\bar{F}_{u}^{\lambda_{j}}(x)\right] \leq n \bar{\lambda}\left[1-\bar{F}_{u}^{\bar{\lambda}}(x)\right]^{n-1},
$$

where

$$
\bar{F}_{u}(x)=\frac{\bar{F}(u+x)}{\bar{F}(u)},
$$

which is the survival function of $X_{u}=X-u \mid X>u$, the residual life of $X$ at time $u \geq 0$. Now, using the transform

$$
H(x)=-\log \bar{F}_{u}(x), \quad u \geq 0,
$$

it follows that that inequality $(0.1)$ becomes

$$
\sum_{i=1}^{n} \frac{\lambda_{i}}{1-e^{-\lambda_{i} H(x)}} \prod_{j=1}^{n}\left[1-e^{-\lambda_{j} H(x)}\right] \leq n \bar{\lambda}\left[1-e^{-\bar{\lambda} H(x)}\right]^{n-1} .
$$

Theorem 3.1 in Kochar and Rojo [2] proves the following inequality:

$$
\sum_{i=1}^{n} \frac{\lambda_{i}}{1-e^{-\lambda_{i} x}} \prod_{j=1}^{n}\left[1-e^{-\lambda_{j} x}\right] \leq n \bar{\lambda}\left[1-e^{-\bar{\lambda} x}\right]^{n-1} .
$$

Replacing $x$ with $H(x)$, the required result follows immediately.

\section{References}

1. David, H.A. \& Nagaraja, H.N. (2003). Order statistics, 3rd ed. New York: Wiley.

2. Kochar, S.C. \& Rojo, J. (1996). Some new results on stochastic comparisons of spacings from heterogeneous exponential distributions. Journal of Multivariate Analysis 59: 272-281.

3. Kochar, S. \& Xu, M. (2007). Stochastic comparisons of parallel systems when components have proportional hazard rates. Probability in the Engineering and Informational Sciences 21: 597-609. 